\title{
ÉTICA Y AMOR EN LA FILOSOFÍA DE EDMUND HUSSERL
}

\author{
Rubén SÁNChez MuÑoz \\ doi:10.11144/Javeriana.uph32-64.eafh
}

\begin{abstract}
RESUMEN
Este ensayo tiene como propósito mostrar las relaciones que hay en la fenomenología trascendental de Edmund Husserl entre la ética y el amor. Por ello se enfatiza la dimensión moral y ética de la persona, y lo importante que resulta el imperativo categórico según el cual cada hombre debe hacer lo mejor posible para mostrar el impacto social de este imperativo en sus circunstancias. Estas reflexiones conducen al tema de la comunidad y en especial a la comunidad del amor, a la que Husserl dedicó importantes reflexiones desde la fenomenología trascendental. El objetivo es mostrar la dimensión ética del amor en Husserl.
\end{abstract}

Palabras clave: ética; amor; imperativo categórico; virtud; comunidad

* Universidad Anáhuac campus Xalapa, Xalapa-Enríquez, México.

Correo electrónico: rubsanchez@uv.mx

Para citar este artículo: SÁNCHEZ MuÑoz, R. (2015). Ética y amor. La filosofía de Edmund Husserl. Universitas Philosophica, 32(64), pp. 179-196, ISSN 0120-5323, ISSN en línea: 2346-2426, doi: 10.11144/Javeriana.uph32-64.eafh 


\title{
ETHICS AND LOVE IN EDMUND HUSSERL'S PHILOSOPHY
}

\author{
RubÉN SÁNCHEZ MuÑoz
}

\begin{abstract}
This essay aims to show the relationships in the transcendental phenomenology of Edmund Husserl between ethics and love. Why it is emphasized in the moral and ethical dimension of the person and how important is the categorical imperative according to which every man must do his/ her best to show the social impact of this imperative in his circumstances. These reflections lead to the theme of the community and to the community of love, in special, which Husserl devoted major reflections from the transcendental phenomenology. The aim is to show the ethical dimension of love in Husserl.
\end{abstract}

Key words: ethics; love; categorical imperative; virtue; community 
El PRIMER LOGRo De LA Fenomenología, dice Guillermo Hoyos (2002), "consiste en el rescate de la persona moral, de su actitud ética, de su capacidad de responsabilidad, de su estar «moralmente bien»” (p. XIx). La ética de Husserl intenta, así, "reconstruir un sentido de sujeto capaz de asumir su responsabilidad en procesos de transformación de la cultura” (Hoyos, 2002, pp. XIV ss.) y, para hacerlo, la racionalidad práctica se convierte en un ideal, en un deber y una exigencia que Husserl formula a través de un imperativo categórico que se encuentra contenido en los cursos de 1908 y 1909 , y que reitera posteriormente.

Así, en sus ensayos sobre Renovación del hombre y de la cultura, Husserl sostiene, recordando a Kant en un sentido nuevo, que cada hombre se encuentra bajo el mandato de un imperativo categórico. Este imperativo dice: “ «Sé hombre verdadero. Conduce tu vida de modo que siempre puedas justificarla en la evidencia. Vive en la razón práctica»" (Husserl, 2002, p. 38). El hombre, en tanto que persona racional, tiene ante sí mismo, por lo tanto, la exigencia axiológica de "hacer en cada momento del tiempo lo que en él sea lo mejor posible y, así, hacerse siempre mejor según las posibilidades que el tiempo ofrece" (Husserl, 2002, p. 38). La ética, por esta razón, la entendió Husserl en este periodo de su vida, como una reflexión en la que se muestra al sujeto la forma de vida racional en la que ha de esforzarse cada día si quiere llegar a ser sí mismo, a ser una persona auténtica. El hombre ético tiene ante sí la obligación de reconocer alegremente la exigencia categórica, "la exigencia de querer hacer, en general y en cada momento de la vida, eligiendo libremente, lo mejor posible y conferirle a su vida entera, según sus posibilidades, el estilo unitario de la vida racional" (Husserl, 2009a, p. 812).

Así pues, vivir humanamente no es vivir simplemente en la pasividad del acontecer histórico. La fe del ser humano en sí mismo, así como la fe de cada cultura en sí misma como parte de la humanidad, exigen para sí valores verdaderos y cada vez más altos. La exigencia moral del ser humano como sujeto de voluntad libre está en participar activamente en la toma de decisiones que a nivel práctico puede contribuir a cambiar el mundo circundante. No obstante, esta es una exigencia absolutamente personal que "transcurre por grados de toma de conciencia de sí mismo y de la responsabilidad por sí mismo" a través de actos 
aislados y ocasionales "hasta el grado de la toma de conciencia de sí mismo y de la responsabilidad por sí mismo universal” (Husserl, 2008, p. 305).

Por ello, cuando dice Husserl que "algo nuevo tiene que suceder", se refiere a que cada ser humano individual, en tanto ser racional, tiene ante sí la posibilidad de decidirse por llevar la vida mejor posible y de orientarse en función de la razón; se trata de un llamado a hacerse cargo de la historia, en primer lugar de la historia personal, porque "lo que deviene en esa vida es la persona misma" (Husserl, 2008, p. 305). La autorrealización personal es un "proceso de devenir" en el que cada hombre se hace a sí mismo un "hombre nuevo" (Husserl, 2002, p. 24). El "combate moral" que ello implica "tiene en toda circunstancia un significado generador de valores" y, además, "eleva la personalidad de quien en él se debate, al nivel de la verdadera humanidad" (Husserl, 2002, p. 2). Esta era para Husserl, desde un punto de vista personal y social, "una exigencia ética absoluta". En esta capacidad esencial del ser humano de actuar libre y activamente desde sí mismo Husserl reconoció los actos específicamente personales (Husserl, 2002, p. 24).

Por otra parte, en el manuscrito de febrero de 1923 intitulado "Valor de la vida. Valor del mundo. Moralidad (virtud) y felicidad", Husserl sostuvo que:

Mi vida es racional, y yo soy racional desde el punto de vista práctico, si en general quiero lo mejor posible y lo cumplo según la mejor posibilidad, y si tomo la decisión de no dejarme llevar nunca, de esforzarme sin excepción hacia lo mejor posible, y de hacerlo y quererlo; de ese modo no sólo soy racional considerado objetiva y accidentalmente, sino conscientemente racional; vivo con intención racional y mi vida misma tiene más valor mediante esa intención. (Husserl, 2009a, p. 800)

Pero allí mismo apuntó, inmediatamente, que el conocimiento de lo mejor posible en cada caso no es suficiente para ser ético, sino que este atributo de la persona solo se alcanza "mediante la libre decisión"1.

1 Por supuesto, se trata aquí del papel que juega la voluntad en este proceso de autoconfiguración, ya que solo a través de la voluntad puede el sujeto querer libremente; además, y esto es importante, Husserl reconoce el lugar que ocupa el entendimiento dentro de este proceso. Afirma, por ejemplo, que no podemos querer un valor sin conocerlo o que es irracional querer una meta que de entrada es imposible, pues "para dejarse motivar por lo valioso hay que lograr tenerlo a la vista" (SánchezMigallón, 2009, p. 45). Husserl mismo expresó que la razón cognoscente es función de la razón práctica y dijo, además, que "el intelecto es servidor de la voluntad" (Hua, VIII, p. 201. Citado por Schuhmann, 2009, p. 115). 


\section{La exigencia ética como virtud}

VALE La PENA RECORDAR LaS ideas que Husserl expone en su artículo publicado en Logos en 1910-11 en el que habla del hombre "bien formado" como aquel que no solo tiene experiencia del mundo, sino también de las formas de valor relativamente superiores. La sabiduría se refiere a estos hombres que experimentan niveles de valor especialmente altos, tanto en el mundo como en la religión, la ética, la estética, la política, etc. Esta sabiduría posibilita, a su vez, una visión del mundo, la cual es, en opinión de Husserl, un "componente esencial de ese hábito humano, aún más valioso, que se nos presenta en la idea de la excelencia acabada y que designa el ser experto de manera habitual respecto de todas las dimensiones posibles de la humana actitud: la cognoscitiva, la valorativa y la volitiva" (Husserl, 2009b, p. 69). Esta sabiduría es la que permite "justificar expresamente las propias actitudes", es decir, juzgar racionalmente sobre los objetos a los que está dirigida esta actitud: "el mundo entorno, los valores, los bienes, las acciones, etc." Así pues, como bien señala Ulrich Melle, Husserl muestra que en la vida cotidiana solo raramente estamos dirigidos a los objetos de manera teórica. "Nuestro comportamiento cotidiano en el mundo está orientado en primera línea emocional y prácticamente” (Melle, 1994, p. 67).

Una sabiduría como esta, sin embargo, no es una cuestión individual sino un asunto cultural, ya que pertenece a una comunidad cultural y a la época en que se vive, son "exigencias vigentes del espíritu común”. Así pues, Husserl se refiere al arte del hombre virtuoso, al arte del que se esfuerza por ser excelente y se impone para sí mismo alcanzar las metas más altas de la idea de humanidad. Esta virtud se define como "arte de la acción correcta", la cual "remite al carácter práctico excelente, y este presupone la perfección como hábito tanto en sentido axiológico como intelectual. A su vez, el empeño consciente por la perfección presupone empeño por la sabiduría en todas sus facetas" (Husserl, 2009b, p. 71).

La ética de Husserl es, por lo tanto, un llamado a la excelencia, a la ảpeti่, que tiene como ideal la "excelencia consumada" y que se desarrolla en dirección del ideal de humanidad. En esta sintonía, dice Husserl, es claro

(...) cómo todos deben esforzarse por ser personalidades excelentes en todos los sentidos y en todo lo posible: excelentes en todas las direcciones básicas de la vida que, por su parte, se corresponden con las especies fundamentales 
de las actitudes posibles; y, por tanto, «expertos» en cada una de estas direcciones en el mayor grado posible, «sabios» en el mayor grado posible en todas y por ello mismo también «amantes de la sabiduría » en el mayor grado posible. Idealmente, cada hombre que se esfuerza es necesariamente «filósofo» en el sentido original de la palabra. (Husserl, 2009b, pp. 70 ss)

Así, Julia V. Iribarne muestra la importancia que juega en el voluntarismo

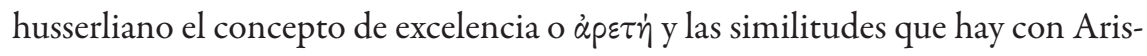
tóteles - de lo que aquí no se hablará. Señala que, para Husserl, "la vida virtuosa o el buen carácter alcanza la plenificación como vida que establece una hexis (hábito) a lo largo de variadas circunstancias, de modo tal que procura un parecido respecto de sí misma, concordante con el telos de la vida" (Iribarne, 1999, p. 375; Husserl, 1987, p. 149). Enfatiza, de este modo, lo importantes que son las tomas de postura conscientes del hombre maduro para "llegar a ser persona".

Estas tomas de posición son imprescindibles en el devenir de la persona, en su génesis histórica, porque de ellas resulta la historia de un yo personal. Por ello, para Husserl, la primera toma de posición verdaderamente importante es la de la responsabilidad ante la historia personal, porque en ella se produce una transformación radical no solo personal sino también intersubjetiva. Y es intersubjetiva porque la virtud o las virtudes no están dadas al ser humano desde su nacimiento, sino que "[son] una latencia a ser actualizada en y por el entrelazamiento intersubjetivo" (Iribarne, 1999, p. 368). La persona se configura solamente por su relación con los otros, con los que comparte no solo un espacio geográfico, sino con los cuales mantiene relaciones a través de la cultura, los fines comunes, los valores, etc.

Desde un punto de vista personal:

El ser humano juzga lo bueno y lo malo, lo valioso y lo que no lo es, y al mismo tiempo estima sus actos, sus motivos, sus medios y sus fines así como el ámbito total de sus posibilidades prácticas. Por fin, estima también su propio "carácter" práctico, sus rasgos, capacidades, disposiciones en la medida en que determinan el modo y la orientación de su praxis posible, que en un principio puede aparecer como un habitus originario anímico que organiza toda actividad, por este camino va generando su propia historia. (Iribarne, 1999, p.377; Husserl, 2002, p. 24)

El ser humano ético es un ser en conformidad consigo mismo que tiene delante de sí una lucha eterna de renovación constante. La exigencia ética de Husserl, 
entonces, consiste en adecuar la acción a lo valioso. Bajo esta exigencia, "toda persona debe lograr también su perfección moral individual, la conformación racional según su peculiar índole personal, propia exclusivamente de él" (Sánchez-Migallón, 2009, p. 46).

Esta lucha "supone una vigilancia que excluye todo permanecer pasivo en la satisfacción" (Husserl, 2009a, pp. 819 ss). Esta vigilancia de sí mismo es la que conduce al yo moral a su autodeterminación y a la educación de sí mismo. En efecto, “(...) el yo moral, el yo de la permanente e interminable educación de sí mismo, es el yo que quiere mejorarse a sí mismo, que quiere volver a crearse de tal modo (a sí mismo como yo), de modo que como yo ético eo ipso solo puede querer el bien" (Iribarne, 2007, p. 71)2. En otra parte de su obra Husserl sostiene que "si el ser humano también entonces persevera, lucha heroicamente y aspira al bien, hace sin duda lo mejor. Sólo así es ético” (Husserl, 2009a, p. 814). Empero, para el filósofo moravo la persona virtuosa es aquella que se sabe persona moral y que, además, lo es de un modo habitual; por lo que no es suficiente realizar actos morales aislados o espontáneos. La persona ética, virtuosa, además, conduce libremente su voluntad hacia lo bueno y lo hace a través de una habitualidad que llega a convertirse para él en una "segunda naturaleza".

\section{Ética y felicidad}

CON LAS NUEVAS TOMAS DE POSICIÓN ante las circunstancias se producen ciertas disposiciones del carácter personal que tienden a repetirse en el flujo de la vida de un sujeto y que hacen de este, en su conjunto, una persona individual ${ }^{3}$. Esta es la razón por la cual, a juicio de Roberto Walton, el imperativo categórico de la ética de Husserl busca lo mejor posible tomando en cuenta "las capacidades de cada persona” (Walton, 2003, p. 6), es decir, el imperativo categórico no puede estar por encima de las capacidades personales porque, de lo contrario, sería imposible su

$2 \mathrm{Al}$ respecto, véase: Hua, XXXVII, p. 162.

3 En este sentido señala Julia V. Iribarne (1999) que "un acto de toma de posición se lleva a cabo como una diathesis como estabilidad del carácter y una hexis, vale decir, un habitus, y también con el sentido contemporáneo del término "actitud", o sea, una disposición hacia la repetición de actos de toma de posición en circunstancias similares" (p. 381). 
realización y esto sería absurdo. El hombre debe exigirse hacer lo mejor posible entre lo alcanzable, por ello "cada hombre tiene, en relación con su esfera práctica, su imperativo categórico individual y en cada caso concretamente determinado" (Walton, 2003, p. 10). Como el propio Husserl afirma en los ensayos de Renovación:

Cada hombre tiene, pues, además de su individualidad, su idea ética individual y su método ético individual, su imperativo categórico individual determinado en concreto para su caso. Sólo la forma general de esencia del hombre ético y de una vida bajo el imperativo categórico formalmente idéntico, es común a todos los hombres en cuanto tales; y comunes son también, naturalmente, todas las normas aprióricas que una ética científica y fundamental (formal, por tanto) sea capaz de deducir de la 'esencia' del ser humano. (Husserl, 2002, p. 43)

Ahora bien, en el manuscrito de 1923, Husserl se plantea una de las preguntas más importantes de la ética: aquella que indaga la relación entre el hombre ético, en tanto ser humano virtuoso, y la felicidad, en términos de Husserl, entre la vida ética y la felicidad o satisfacción. Ante este cuestionamiento, el filósofo sostiene que la vida ética da la satisfacción de sí mismo, y que esta satisfacción es condición de posibilidad de cualquier otra satisfacción. "Ella me da valor y es reconocimiento de mi valor o conformidad respecto de mi valor. La lucha por la vida ética es lucha por mí, para que yo me pueda respetar" (Husserl, 2009a, p. 818). En esta idea del respeto por sí mismo se alcanza la imagen de la persona como fin en sí mismo, ya que la dignidad de la persona estriba en su valor absoluto. Frente a ella, todos los demás fines pueden reemplazarse, ser o no ser propuestos. Justo en este sentido, Husserl mantiene que "el sujeto puede llegar a conocer que el poder, el dinero y otros semejantes, no son verdaderos valores absolutos, que la tendencia incondicionada hacia tales fines ha sido incondicionada debido a la ceguera para lo verdadero y para el valor" (Ferrer y Sánchez-Migallón, 2013, p. 151)4.

Desde el punto de vista práctico, Husserl afirma que "el cumplimiento de mi deber no me hace dichoso" (Husserl, 2009a, p. 818), ya que el cumplimiento del deber, por ende, no es suficiente para ser feliz, pues la felicidad no se refiere solamente a un asunto personal individual, de un sujeto aislado que sin duda está

Ms, E III 6, 6a. 
expuesto a incurrir en el error o a dejarse cegar por fines egoístas. Por ello, afirma también que la verdadera dicha "es la alegría por el triunfo de lo mejor que uno se propone, y el éxito de lo mejor para todos los que uno ama, y finalmente para todos los seres humanos" (Husserl, 2009a, p. 819). Agrega , pensando por supuesto en las relaciones humanas a través de la empatía, que "sólo puedo ser feliz propiamente si no me acuerdo de la desdicha de los demás" o que "la más alta alegría posible (...) es imposible; y si fuera posible en la forma en que me hiciera sordo para la pena ajena y para la propia, entonces sería indigna y mala" (Husserl, 2009a, p. 819). Lo anterior nos hace pensar ciertamente en la unión que existe entre la persona individual y la comunidad, puesto que la ética se da en el contexto de las relaciones sociales. En esta vida social el deber del ser humano es mantenerse fiel a sí mismo, es decir, a sus valores, y esforzarse prácticamente por hacer y querer el bien, aunque sea en un círculo reducido, porque en la conformidad consigo mismo, "el correlato de la vida personal que sea la mejor posible a partir de la intención de querer lo mejor posible y actuar según las mejores fuerzas, es el centro de la felicidad" (Husserl, 2009a, p. 804).

\section{Centramiento y descentramieno: la vida en común}

En EL TERCER ARTículo que Husserl publicó en Kaizo aborda el problema de la renovación "como problema ético individual" para mostrar que "la ética no es mera ética individual, sino también ética social" (Husserl, 2002, p. 22). Pues bien, como recuerda Guillermo Hoyos, Husserl le escribió a Albert Schweitzer que el sentido de la palabra renovación era para él el de "conversión ética y de configuración de una cultura ética universal de la humanidad" (Hoyos, 2002, p. viII). Para Husserl, la renovación "pertenece con necesidad de esencia al desarrollo del hombre y de la colectividad humana hacia la humanidad verdadera” (Husserl, 2002, p. 11). Husserl pensó que era propio del imperativo categórico aspirar a una forma superior de comunidad, al igual que Lévinas, reconoció que estamos en comunicación con los otros a través de actos sociales y que en esta comunicación "entramos en contacto unos con otros, formamos una unidad personal de nivel superior” (Husserl, 1987, p. 148).

En el horizonte de la vida comunitaria el hombre ético, esto es, aquel que se esfuerza por hacer de sí mismo lo mejor posible, sirve también de modelo y ejem- 
plo para los demás. En él y en sus acciones los otros encuentran la fuerza motivante que los impulsa a buscar también el mejoramiento de sí y de los demás. Por ello, Iribarne habla de la "paradoja del centramiento descentrado" que este movimiento de la subjetividad conlleva; de acuerdo con los análisis de Husserl, cada persona trata de preservarse a sí misma en el sentido "centrípeto" del cuidado de sí y de su identidad personal. "El término "preservación de sí mismo" alude al centro unitario que se mantiene a pesar de las modificaciones, abarca tanto la capacidad de modificarse como las modificaciones fácticas" (Iribarne, 2009, p. 59). En las tomas de posición, en las que el yo se hace de "convicciones firmes" como propiedades de su yo, se refleja la constante renovación en que vive la persona en constante preocupación y educación de sí, en las que intenta ser fiel a sí mismo. A esta preocupación, entre otras cosas, es a la que se refiere la experiencia de centramiento.

La preservación de sí mismo del ser humano como ser histórico, podría conducirnos ciertamente a posiciones egoístas, como lo que ocurre, por ejemplo, en la filosofía de Hobbes. De acuerdo con Hobbes, el hombre es egoísta, y es su egoísmo el que le conduce a la búsqueda de la autoconservación y al cuidado de sí mismo. Dado que "el hombre es un lobo para el hombre", los seres humanos tienen que establecer un contrato y fundar el Estado y, además, entregar su voluntad a cambio de sus vidas; en este contrato social late la idea de que la felicidad de cada uno está unida a la de los demás, "pues cada uno sólo puede lograr la máxima felicidad propia en la medida en que haga objetivo suyo la mayor felicidad de todos" (San Martín, 1994, p. 285). A juicio de San Martín, el valor de Hobbes para Husserl, y en general para la fenomenología, radica en que en su teoría se puede apreciar "la idea de Estado exigida por la razón, en caso de que el hombre fuera un ser meramente egoista" (San Martín, 1994, p. 286)5. La postura de Hobbes, sin embargo, incurre en una falacia: generaliza la actitud egoísta del ser humano y olvida que en muchas ocasiones el hombre también actúa por motivos que no son egoístas. Para Husserl, el ejemplo más claro de ello es la experiencia del amor.

Como quiera que sea, la coincidencia entre la ética de Husserl y la postura de Hobbes está precisamente en el principio de autoconservación, pero Husserl da un paso más allá. Asume que la persona no vive su vida de manera solipsista, 
"sino una vida ética en común, una vida doblemente personal y, sin embargo, unitaria” (Husserl, 2009a, p. 805). Es decir,

estamos en comunicación mediante actos sociales. No vivimos uno junto al otro, sino uno en el otro. Nos determinamos el uno al otro de persona a persona, de yo a yo, y nuestra voluntad no va sólo a los otros como cosas del mundo circundante, sino que va a los otros, se prolonga hasta el interior del querer del otro, que es el querer del otro y al mismo tiempo nuestro querer. (Husserl, 2009a, p. 805)

Esta vida en común como vida ética, en la que se da la experiencia del descentramiento como vivencia centrífuga, Husserl la explica como una síntesis de polos a través de una "unidad sintética personal a partir de la libertad". En ella, "cada yo se vincula libremente con los otros y, eventualmente, ingresa con ellos en forma éticamente libre en una "comunidad de amor", libremente hace suyos los valores del otro o los reconoce como propios en espíritu y en verdad y se los apropia, y los otros por su parte también" (Husserl, 2009a, p. 806). En la comunidad, en la que vive cada yo como yo polo, o como yo centro, en el sentido de un yo de comportamiento libre, que se deja guiar por criterios racionales y que es origen y fuente de sus actos, "se constituyen sistemas de polos y unidades vitales correlativas que tienen el carácter de una vida que no tiene polos aislados, independientes y despreocupados de los otros actores, sino muchos polos que "participan" en cada acción y que son todos "responsables" de ella" (Husserl, 2009a, p. 806).

El mundo circundante es un mundo en común en el que cada yo como sujeto activo de su acción personal y como objeto-sujeto del contenido de su acción (Husserl, 1987, p. 144) intenta realizar su mejor vida posible a través de su esfuerzo constante. En este esfuerzo, el yo como polo de afecciones y de acciones, hace posible una síntesis ética en la que los otros co-realizan su mejor vida posible, pero ello solo porque el yo polo no vive fuera "sino en los otros". Así pues, el valor de la vida está en la ética, en la actitud radical de vivir en la búsqueda de elevar la existencia, tanto personal como ajena, a su nivel más alto:

Valor de la vida es la vida en todas las circunstancias, ya como ética; valor de la vida para el individuo que reconoce su tarea ética y la asume. Valor de la vida sólo lo es, rectamente, si yo, el que actúa, veo un horizonte abierto de vínculos sociales amorosos y comunidad de trabajo, en el que todos, en pro- 
medio, avanzamos y podemos ayudarnos en el enaltecimiento de la existencia. Eso ya es más y da a la vida un valor más alto. (Husserl, 2009a, p. 820)

Así, el yo puede ser plenamente dichoso, dice Husserl, solo si la humanidad puede serlo como un todo. Por ello la reflexión sobre la felicidad conduce, tarde o temprano, a la experiencia de descentramiento, ya que, como se mencionó arriba, nadie podría confesarse plenamente feliz al considerarse un individuo aislado, o ignorando, o no queriendo ver el mal que aqueja a los demás. "Si la persona alcanza niveles altos de valoración y de responsabilidad, sea por amor o por reflexión o por ambos, sabe que es inalcanzable la felicidad mientras los demás no son felices (...) La imposibilidad de vivir la felicidad es la medida del descentramiento" (Iribarne, 2009, p. 64).

\section{El amor ético y la comunidad del amor}

Julia V. IRIBARne AFIRMa que la mayor preocupación de Husserl como pensador ético "se vincula a la idea -en sentido kantiano- de una convivencia universal armónica, que abarque en sí a pueblos y naciones y a las personas que los configuran" (Iribarne, 1990, pp. 51 ss). Pues bien, esta convivencia universal armónica la encuentra Husserl en el amor, específicamente en el amor ético. A propósito de ello, Husserl sostuvo alguna vez que el amor en sentido auténtico era uno de los problemas fundamentales de la fenomenología. "Es un problema en sus fuentes elementales intencionales así como en sus formas reveladas de la intencionalidad que se manifiesta en las profundidades, en las alturas y en las extensiones universales de la intencionalidad" (Crespo, 2012, p. 16) ${ }^{6}$.

El amor, dice Husserl, es "una disposición duradera" y "un hábito práctico permanente". En su ejecución, señala, no solo se da una "activa complacencia en la individualidad personal del ser amado, en su conducta total, en su comportamiento activo y pasivo hacia su circunmundo, en la expresión de su individualidad en el amor o en su corporalidad en general", sino también "el «contacto» personal con el ser amado y hacia la comunidad en vida y aspiración en la que es tomada su vida en mi vida, es decir, su aspiración en mi aspiración en tanto mi

6 Ms, E III 2/36b. Véase, también: Schuhmann, 2009, pp. 73 ss. 
aspiración y mi voluntad se realizan en las suyas y en su obrar realizante, así como las suyas en las mías" (Husserl, 1987, p. 139). Así pues, sostiene Husserl poco después, "los amantes no viven uno junto a otro o simplemente uno con otro, sino uno en otro, actual y potencialmente. Llevan conjuntamente todas las responsabilidades y se encuentran solidariamente unidos, incluso en el pecado y en la culpa" (Husserl, 1987, p. 140).

Así pues, el amor primigenio es el amor dual que se da de persona a persona. Esta solicitud amorosa por el otro o amor al prójimo da lugar al amor ético en el que el otro se encuentra siempre en el horizonte de mi vida y al revés, yo en el horizonte de la suya. "Llevo a los otros en mí" afirma Husserl. A este encuentro recíproco que se da entre cada sujeto en el horizonte de la vida del otro es a lo que Husserl llama amor ético (Walton, 2003, p. 12). El paradigma de este amor en el que el filósofo pensó es "en el infinito amor de Cristo a todos los hombres y en el amor humano en general que ha de despertar el cristiano en sí mismo y sin el cual ningún verdadero cristiano podría ser tal” (Husserl, 1987, p. 140). Además, sostuvo:

El amor cristiano es, ante todo, únicamente amor. Pero se encuentra vinculado con la aspiración (necesariamente motivada por el amor) a hacerse una comunidad de amor lo más amplia posible. De este modo, la aspiración a «entrar en relación» con los hombres, a abrirse a ellos y a descubrirlos para sí, apunta, en conjunto, hacia una posibilidad práctica cuyas fronteras se encuentran fijadas a través del amor ético. (Husserl, 1987, p. 141)

De acuerdo con los análisis husserlianos, el amor tiene dos características esenciales. La primera se refiere al amor como revelador de la individualidad personal. Según Ulrich Melle, citado por Iribarne (2007): “El ser más profundo de la persona y la raíz más profunda de su identidad no consiste en la razón ni en la aspiración racional sino en el amor" (p. 206). En palabras de Husserl, citado por Crespo (2012):

El auténtico yo ama, se entrega amantemente a su auténtico fin, y su cuidado es cuidado amante. La vida auténtica es, absolutamente, vida en el amor lo cual significa totalmente lo mismo que 'vida en el deber absoluto'. Lo que quiero lo caracterizo con las palabras 'yo debo eso'. Sigo una exigencia. Aquí sigo lo que me apela de un modo completamente personal y esto no es otra cosa sino lo que, en el sentido más profundo, amo, lo que en el sentido más 
hondo quiero. Desde mí mismo y puramente desde mí mismo no puedo querer sino lo que amo personalmente. El amor es la dirección del yo a aquello que atrae de un modo completamente individual a este yo. $(23)^{7}$

De este modo, como puede apreciarse, el amor está en estrecha correlación con el imperativo categórico. El ser humano, como sujeto de autorreflexión y sujeto moral que decide y toma posturas valorativas y prácticas, quiere y opta por el bien; determina por tanto, ser un hombre bueno; sabe, recordando la máxima socrática, que la vida "no tiene valor vivida de cualquier modo" (Husserl, 2002, p. 48).

Respecto del amor y la persona individual, Husserl pone el ejemplo de la vocación como una experiencia peculiar donde se da una relación con un género de valores que, dice, “son objeto de amor «puro»". En la vocación, la persona entrega su vida completamente a la realización de esos valores que aprecia, porque en ella se da "un amor personal de devoción exclusiva”. Yo, afirma Husserl (2002), "puedo respetar por entero y apreciar valores heterogéneos, pero lo que no puedo es amarlos desde el centro más íntimo de mi persona - «con toda mi alma »-: amarlos como los míos, como aquellos a los que yo mismo, tal como soy, pertenezco inseparablemente" (p. 30).

La segunda nota importante del amor es que este constituye un elemento fundante de la comunidad ética. Por ejemplo, yo deseo la bondad no solo para mí, sino para toda la humanidad. Porque mi vida no es solitaria, reconozco la dignidad de cada co-sujeto. Así, "el ideal comunitario es el de una comunidad de sujetos racionales que aspiran a serlo y que se ponen a sí mismos como tales, pero no aisladamente, sino uno a otro en una voluntad universal" (Husserl, 1987, p. 155). Se trata, por tanto, de una comunidad de voluntades, de una comunidad en el querer. El individuo que reconoce el valor de la vida en la razón y la moralidad como valor deseable para todos los hombres que buscan el bien, reconoce también el valor de una comunidad de hombres de bien. Como apunta Karl Schuhmann (2009), "en la comunidad de amor se llega, por una parte, decididamente al Otro en su modo propio individual, irreemplazable y peculiar" (p. 76).

Con todo, al distinguir Husserl entre distintos tipos de comunidades, se refiere a la comunidad ética o comunidad del amor como una comunidad de nivel

7 Ms. A V 21/90a. 
superior. Como hemos visto, la persona se valora a sí misma como un sujeto de valor absoluto, valor descubierto en sí mismo y asignado a los otros, ya que el horizonte ético no le compete únicamente a la persona individual, sino que es un horizonte intersubjetivo. En este horizonte la persona reconoce en los demás su valor como individuos. "Las personas son, por principio, unidades de desarrollo infinito (...) las personas devienen y son objetos para realizaciones personales" (Husserl, 1987, p. 154).

En este despliegue de la persona se da un "acrecentamiento axiológico" que se dirige a un máximo de valor; es decir, la persona en su despliegue temporal aspira siempre a alcanzar los valores más altos, que fungen como polos de atracción hacia los cuales se encamina y dirige sus acciones. Sirven, a su vez, como motivos para nuevas tomas de posición. Así, una vez que la subjetividad toma conciencia de sí, "descubre en sí misma la idea de un amor perfecto" (Walton, 2010b, p. 92). De este modo, nuestra experiencia del amor no es más que la raíz de una idea teleológica del amor, es decir, "del polo ideal de un amor perfecto que trasciende la finitud" (Walton, 2010b, p. 93). Se trata, en últimas, de un despliegue ascendente que inicia ciertamente en el amor pulsional, en el amor sensible, pero que se convierte, con el tiempo, en un amor espiritual por la persona y en un amor racional que se funda en la autonomía del sujeto. "El amor -señala Walton- responde a la vez al llamado de un valor y a la decisión racional de querer el bien de la persona amada" Así pues, en esta experiencia "se da un acrecentamiento de valor que se orienta hacia el polo ideal del amor perfecto" (Walton, 2010b, p. 93).

Por ello, el amor es visto por Husserl como el bien mayor (summum bonum) (Vargas, 2007, p. 88) y así puede convertirse en el motor de toda la vida del ser humano, de modo que orienta todo el desarrollo de la subjetividad en función de su idea-fin. Por consiguiente, el amor ha de convertirse para el ser humano, en una "orientación voluntaria" que lo lleva a vivir una vida auténtica, una vida en la autorresponsabilidad, digna y dichosa. 
Crespo, M. (2012). El amor como motivo ético en la fenomenología de Edmund Husserl. Anuario filosófico 45(1), pp. 15-32.

Hoyos, G. (2002). La ética fenomenológica como responsabilidad para la renovación cultural. Renovación del hombre y de la cultura. Cinco ensayos (pp. VIIXXXIII). (Trad. A. Serrano de Haro). Barcelona/México: Ánthropos/UAM.

Husserl, E. (2009a). Valor de la vida. Valor del mundo. Moralidad (virtud) y felicidad. (Trad. J.V. Iribarne). Acta fenomenológica latinoamericana, III, pp. 789-821.

Husserl, E. (2009b). La filosofía, ciencia rigurosa. (Trad. M. García-Baró). Madrid: Encuentro.

Husserl, E. (2002). Renovación del hombre y de la cultura. Cinco ensayos. (Trad. A. Serrano de Haro). Barcelona/México: Anthropos/UAM.

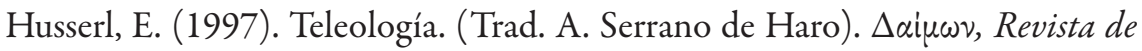
Filosofía, 14, pp. 5-14.

Husserl, E. (1987). El espíritu común (Gemeingeist) I y II (1921). (Trad. C. Moreno). Thémata, 4, pp. 131-158.

Iribarne, J.V. (2009). Preservación de sí mismo. La paradoja del centramiento descentrado. Acta fenomenológica latinoamericana, III, pp. 55-66.

Iribarne, J.V. (2007). De la ética a la metafísica. En la perspectiva del pensamiento de Edmund Husserl. Bogotá: Universidad Pedagógica Nacional/San Pablo.

Iribarne, J.V. (1999). Areté como ejercicio de excelencia y como telos en la ética de Husserl. Areté. Revista de fllosofía, XI(1-2), pp. 367-385.

Iribarne, J.V. (1990). La problemática ética en el pensamiento de Husserl. Diánoia, 36, pp. 51-60.

Melle, U. (1994). La fenomenología de la voluntad de Husserl. Ideas y valores, 43(95), pp. 65-84.

Sánchez-Migallón, S. (2009). El alcance de la exigencia moral de racionalidad en Husserl. Racionalidad práctica, 212, pp. 41-47.

San Martín, J. (1994). La fenomenología como teoria de una racionalidad fuerte. Madrid: UNED. 
Schuhmann, K. (2009). Husserl y lo politico. (Trad. J.V. Iribarne). Buenos Aires: Prometeo Libros.

Schuhmann, K. (1989). La idea de Husserl de la filosofía. A. Zirión. (Comp.), Actualidad de Husserl (pp. 147-176). México D.F.: UNAM/Alianza Editorial/Fundación Gutman.

Vargas Bejarano, J.C. (2007). La ética fenomenológica de Edmund Husserl como ética de la "renovación" y ética personal. Estudios de Filosofía, 36, pp. 61-93.

Walton, R. (2010a). El giro teleológico como retorno a los orígenes: La fenomenología de la excedencia. Pensamiento y cultura, 13(2), pp. 127-140.

Walton, R. (2010b). Teleología y teología en Edmund Husserl. Estudios filosóffcos, 45, pp. 81-103.

Walton, R. (2003). Imperativo categórico y Kairós en la ética de Husserl. Tópicos. Revista de filosofía de Santa Fe, 11, pp. 5-21. 